\title{
Smart Solar Tracker
}

\author{
${ }^{1}$ Shruti Dhananjay Gaikwad, ${ }^{2}$ Snehal Maruti Gunaware, ${ }^{3}$ Shivangi Jha, ${ }^{4}$ Sonal I Shirke \\ ${ }^{1,2,3}$ Student, ${ }^{4}$ Professor, Pimpri Chinchwad College of Engineering , Pune, India,
} 1 shrutigaikwad1998@gmail.com, ${ }^{2}$ snehalmgunaware123@gmail.com, ${ }^{3}$ shivangi.jha201@gmail.com Abstract - The Smart Solar Tracker resembles the structure of Sunflower wherein, the petals act as a Solar cell and so different circuits are designed to control the movement of these cells. The circuit consisting of an LDR sensor is used to detect the maximum intensity of light and accordingly the movement of the petals will take place in that direction. During the night time, when no light is detected the petals get closed. The vibration sensor is placed on the leaves to detect the heavy hailstorms and prevent the system from damage by closing the petals which follow the helical path. This results in self cleansing action of petals during closing and opening of the petals. As a result the Smart Solar Tracker is $\mathbf{9 0 \%}$ more efficient than the Traditional Solar panels installed.

Keywords - Smart Solar Tracker, LDR, Vibration sensor, Helical path, Self cleansing, Dual axis tracker.

\section{INTRODUCTION}

Economic development is one of the most important factors for developing India. Renewable energy resources (Solar, wind \& biomass) is one of the most fundamental of natural resources that must be harnessed for rapid economic development. In order to minimize irreversible climatic effects, the International energy agency, estimates that nearly $50 \%$ of global electricity supplies will need to come from renewable energy sources in order to have $\mathrm{CO} 2$ emission by 2050. Traditional solar panels installed in households are fixed at one place. So, the power output obtained is less. It is also difficult to clean and maintain the Solar panels. So, the alternative to this problem is Smart Solar Tracker. Smart Solar Tracker is a movable dual axis tracker and while opening and closing petals self cleansing action also takes place. It also improves the efficiency and also produces more power at output by absorbing more sunlight. The LDR sensors are pointed towards the sun and wherever the maximum light is present, petals of Sunflower will face towards it. This produces maximum power for a longer time. This feature makes it different from the traditional panels. It is also user friendly and also easily reprogrammable.

\section{METHODOLOGY}

\section{A. Block Diagram}

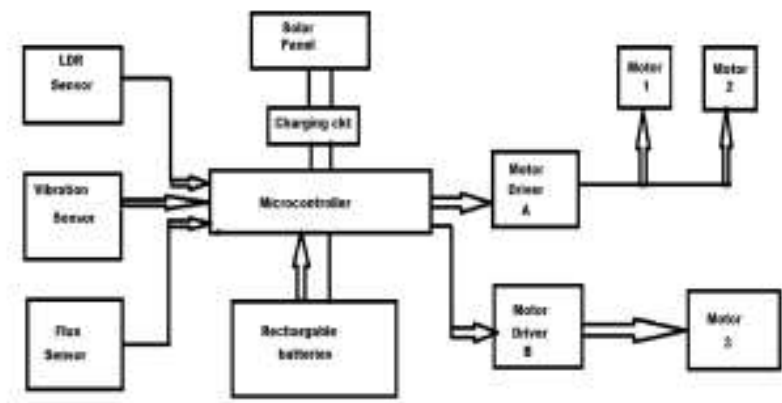

Fig.1 Block Diagram of Proposed System
MICROCONTROLLER: Smart Solar Tracker uses a microcontroller as a key component.

PHOTOVOLTAIC SOLAR SOLARPLATE: In Smart Solar Tracker, photovoltaic solar plates are the main component. To absorb the solar energy and to convert it into the electrical energy, these plates are required.

LDR: It detects the intensity of the sun and accordingly helps to move the Smart Solar Tracker. Petals of Smart Solar Trackers will move in the direction that have more intensity.

POTENTIOMETER: At times when intensity of sun will be variable, potentiometer will change the intensity of LDR so that the minimum required energy for a day can be generated.

VIBRATION SENSOR: Vibration sensor senses the vibration caused by the heel storm and accordingly the petals of Smart Solar Tracker will be closed.

DC MOTOR: For the movement of Smart Solar Tracker DC motors are required. One DC motor will open the petals of the Smart Solar Tracker. One DC motor will move the Smart Solar Tracker according to the movement of the sun.

MOTOR DRIVER: Motor drivers are required to drive the motor.

Here is the code for working on the Solar System.

Code:

int shock $=0$;

void $\operatorname{setup}()$

\{

pinMode(2,INPUT);//shock

pinMode(9,OUTPUT);//led2

digitalWrite $(9,0)$;

\}

$\operatorname{void} \operatorname{loop}()$

\{

shock $=$ digitalRead $(2) ;$ if $($ shock $==$ HIGH $)$ 
\{

digitalWrite(10,HIGH);

\}

else

\{

digitalWrite(10, LOW);

\}

\}

\section{B. Flowchart :}

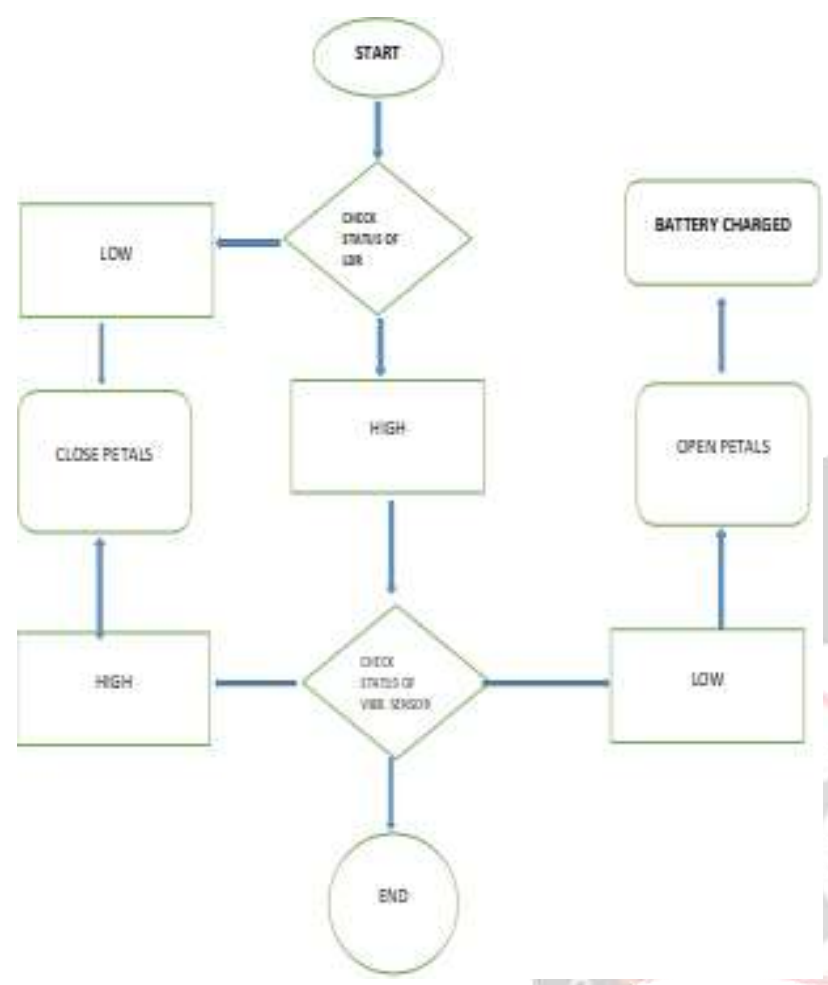

Fig.2 Flow Chart of Proposed System

The working status of the system is given as follows:

If the sunlight is present the status of the system will be high and then further the system will check the status of the vibration sensor. If any external factors like hail storm etc..are detected the status of vibration sensor will be high or else the petals will be opened and charging of battery will take place. Whereas, if the sunlight is not present the status of the system will be low at the initial condition only and thereby petals of the sunflower will be in a closed state.

By employing a low power microcontroller and low power sensor, the model meets the desired capabilities of providing as much as output as possible while still being affordable to consumers. The structure of the system is designed using axial movement of the solar plates. By choosing the optimal angle of the light intensity falling on the photoresistor(LDR), the control of solar plates takes place. The photoresistors are used to detect the light intensity. Four light sensors namingly cadmium sulphide(Cds) are placed in four different quadrants on the plain plastic piece and additional two small pieces has been placed perpendicular to the straight plain piece to divide the four sensor in the form of four different blocks of $(2 * 2)$.
These sensors are used as comparators of light intensity. Any sensor out of four sensors detecting higher intensity of light will trace the position of the sun. In this prototype the purpose of doing so is that if all four sensors are equally illuminated by sun their resistance level will be same if one of the sensors come undershadow then the controller of tracking system will sense the deviation of signal and it will set the driver in motion to correct misalignment between sun's ray and the surface normally.

\section{RESULTS}

Testing of Solar plates:

Table 1: voltages at different time interval

\begin{tabular}{|l|l|}
\hline TIME & VOLTAGE READING \\
\hline 9:00 A.M. & $2.3 \mathrm{~V}$ \\
\hline
\end{tabular}

10:30 A.M.

$2.8 \mathrm{~V}$

12:00 P.M

3.0 V

3:00 P.M.

3.0 V

5:00 P.M.

$2.7 \mathrm{~V}$

6:30 P.M.

$2.1 \mathrm{~V}$

7:00 P.M.

$0.9 \mathrm{~V}$

An electric cell is a device that converts the energy of sunshine directly into electricity by photovoltaic effect. Since, the readings are taken at different amounts, intensity and strength of signal is varied.

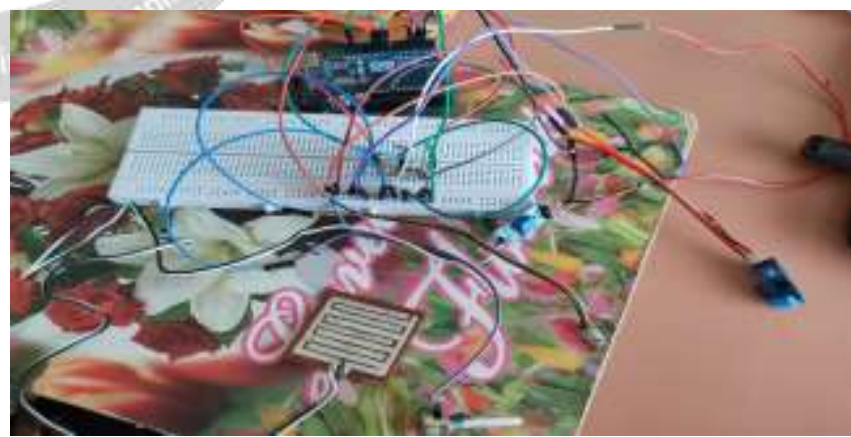

Fig.3 Testing of Vibration Sensor

In order to keep tracking the working module, a vibration sensor is employed. The fundamental principle of a sensor is to limit the measuring points so as to minimise the further distortion. 


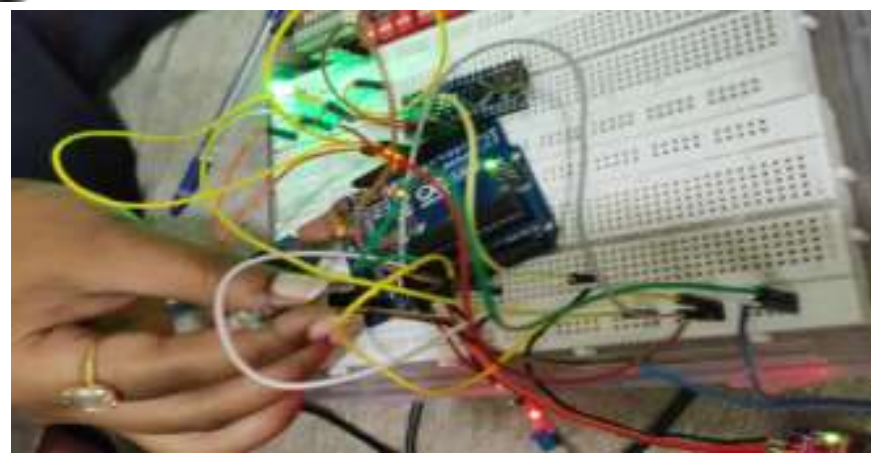

Fig.4 Testing of LDR

The orientation of the solar panels could be an important problem. The apparent position of the sun in relation to collecting points is continuously changing throughout the day. So, we'll need to constantly change the position of the panels to trace the sun and to capture the maximum incident beam.

\section{OTHER EXPERIMENT RESULTS}

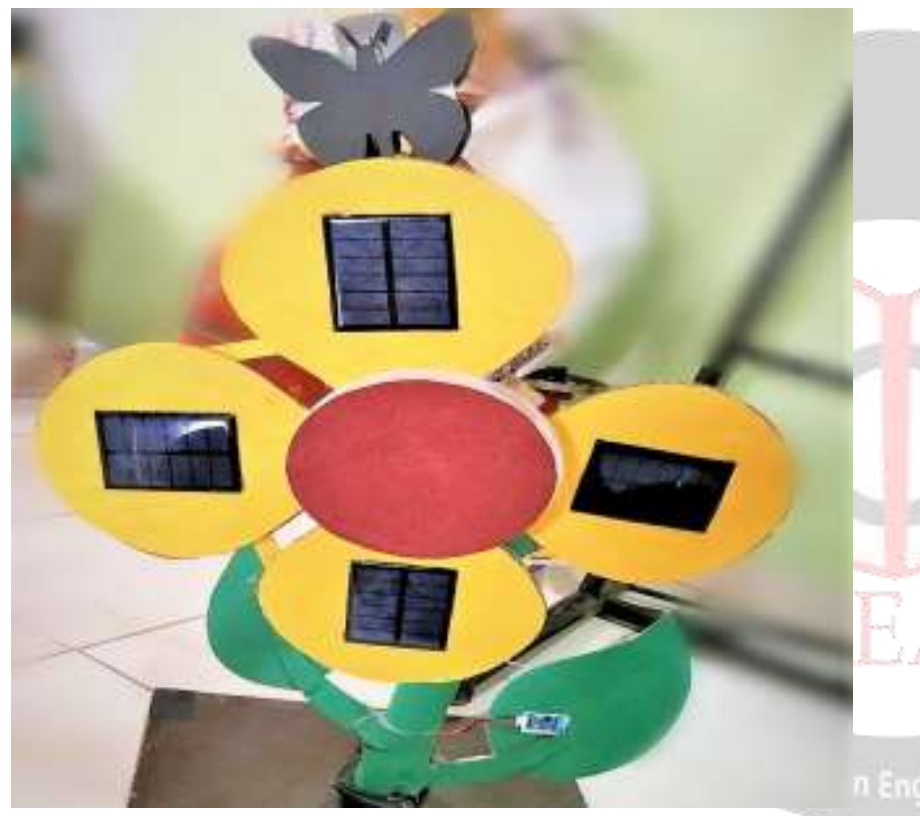

Fig. 5 System of Smart Solar Tracker

\section{CONCLUSION}

The tracking of alternative energy is allotted out under clear sky and partly cloudy sky. The sun tracking scheme leads to a substantial saving in energy. It's an easy and price effective control implementation. It's a capability to maneuver the 2 axes simultaneously within their respective ranges.The tracking system is slightly laboured by wind speed thanks to light weight frame structure. Preplaning the required electrical device height from the reference can avoid unwanted rotation of the electrical device. The system has one second time interval, but this time interval is often reconfigured through programming.It's also applicable to moving platforms with the sun tracker. Smart Solar Tracker technology has higher energy compared with both fixed electrical devices and single axis Solar tracking technologies.

\section{ACKNOWLEDGMENT}

We wish to acknowledge the support of the many people that have contributed to our project. We would like to thank our guide, Mrs S.I.Shirke and Assistant professor within the Electronics and Telecommunication Department, for her encouragement and valuable guidance. They motivated us greatly which contributed tremendously to our work.We would like to thank Dr.N.B.Chopade, HOD in Electronics and Telecommunication Department and Dr.A.M.Fulambarkar, principal, Pimpri Chinchwad College of Engineering for his support. We also are glad to specific our gratitude and due to our parents and friends for their constant inspiration and encouragement.

\section{REFERENCES}

[1] T. C. Mallick, M. S. Munna, B. Barua, K. M. Rahman, "A design \& implementation of a single axis solar tracker with diffuse reflector",2014 $9^{\text {th }}$ International Forum on Strategic Technology (IFOST), pp. 289-293, 2014.

[2]A. Kassem, M. Hamad, "A microcontroller-based multifunction solar tracking system", Systems Conference (SysCon) 2011 IEEE International, pp. 13-16, 2011.

[3]Minor M. Arthuro, High-Precision Solar tracker System, Proceedings of the World Congress on Engineering 2010, vol II, London, UK, June 30 July 2, 2010.

[4]J.Beltrán, García-Beltrán, Design, Manufacturing and Performance Test of a Solar Tracker Made by an Embedded Control, 4th Congress of Electronics, Robotics and Automotive Mechanics, 2007.

[5] J. V. Patil, J.K. Navak V.P. Sundersingh, 1997, Design, Fabrication and Preliminary Testing of a Two-Axes Solar tracking System, ERIC International Energy Journal, vol. 19, No.1.

[6] T. Markvart [2007]. "Solar Electricity", Wiley.

[7] J. Beltrán A., J. L. González Rubio S. y C. D. García-Beltrán, Design, Manufacturing and Performance Test of a Solar Tracker Made by an Embedded Control, 4th Congress of Electronics, Robotics and Automotive Mechanics, 2007.

[8] Minor M. Arthuro, High-Precision Solar tracker System, Proceedings of the World Congress on Engineering 2010, vol II, London, UK, June 30 July 2, 2010.

[9] J. V. Patil, J.K. Navak V.P. Sundersingh, 1997, Design, Fabrication and Preliminary Testing of a Two-Axes Solar tracking System, ERIC International Energy Journal, vol. 19, No.1

[10] Helwa NH, Bahgat ABG, El Shafee AMR, El Shenawy ET [2000]. "Maximum collectable solar energy by different solar tracking systems", Energy Sources, pp 22-34.

[11] Poulek V, Libra MA [2000]. "Very simple solar tracker for space and terrestrial applications", Solar Energy Mater Solar Cells, pp 60: 99-103.

[12] Abdallah S, Salem N [2004]. "Two axes sun tracking system with PLC control", Energy Convers Manage, pp 45 (11-12). [10] Neville RC [1978]. "Solar energy collector orientation and sun tracking mode", Solar Energy, pp 20(1):7-11.

[13] R. A. Messenger, J. Ventre [2003]. "Photovoltaic Systems Engineering”, CRC Press.

[14] Roth P, Georgiev A, Boudin H [2005]. "Cheap two axis sun following device", Energy Convers Manage pp 46.

[15] Clifford MJ, Eastwood D [2004]. "Design of a novel passive solar tracker", Solar Energy, pp 77(3):269-80.

[16] Roth P, Georgiev A, Boudin H [2004]. "Design and construction of a system for sun-tracking", Renewable Energy, pp 29(3):393-402. 